\title{
OLdER MATERnAL AGE AND CARDIOVASCULAR AND METABOLIC DISEASE OUTCOMES: A RETROSPECTIVE COHORT STUDY USING DATA FROM POPULATION -BASED ELECTRONIC MEDICAL RECORDS
}

\author{
Sharon Orbach-Zinger, Becca Feldman, Maya Leventer-Roberts, Moshe Hoshen, Ran Balicer, Leonid .A. Eidelman \\ Rabin Medical Center, Petach Tikva, Israel.
}

\section{BACKGROUND AND GOAL OF THE STUDY}

In this study we aimed to evaluate whether women with advanced age at their first birth have more intermediate cardiovascular and metabolic health (cardiometabolic) outcomes that occur by age 45 .

\section{MATERIALS AND METHODS}

- This retrospective, longitudinal, population-based cohort study included women aged 34-39 at baseline (2004-2006) who were followed through until age 45.

- All data was extracted from a large comprehensive electronic medical record database from Clalit Health Services.

- Women at baseline were identified as parous or nulliparous and then followed up until 2016 and further divided into three groups: women who gave birth to their first child between the age ages of 34-39, those who gave birth to their first child between the ages of 40-44, and a group of persistent nulliparous women.

- The rate of both adverse pregnancy events and cardiometabolic diseases at age 45 were compared across these three groups and to women in the general population.

- Main outcomes measures included type 2 diabetes, obesity, hypertension, cardiovascular disease, and Framingham risk score.

TABLE 1: INTERMEDIATE CARDIOMETABOLIC OUTCOMES AT AGE 45 BY THE GENERAL POPULATION, YOUNGER PARTURIENTS1, OLDER PARTURIENTS2, AND PERSISTENT NULLIPAROUS WOMEN

\begin{tabular}{|c|c|c|c|c|c|c|}
\hline $\begin{array}{l}\text { Outcomes } \\
\text { (at age 45) }\end{array}$ & $\begin{array}{c}\text { GENERAL } \\
\text { POPULATION* }\end{array}$ & $\begin{array}{c}\text { YOUNGER } \\
\text { PARTURIENTS }\end{array}$ & p-value & $\begin{array}{c}\text { OLDER } \\
\text { PARTURIENTS }\end{array}$ & $p$-value & $\begin{array}{c}\text { PERSISTENT } \\
\text { NULLIPAROUS }\end{array}$ \\
\hline $\mathbf{N}$ & 106,050 & 952 & & 673 & & 8,354 \\
\hline Diabetes & $2.3 \%$ & $1.3 \%$ & 0.46 & $1.6 \%$ & 0.24 & $2.3 \%$ \\
\hline Hypertension & $5.7 \%$ & $1.8 \%$ & 0.16 & $3.0 \%$ & 0.67 & $3.4 \%$ \\
\hline Obesity & $21.0 \%$ & $15.8 \%$ & 0.82 & $15.2 \%$ & 0.01 & $19.7 \%$ \\
\hline Cardiovascular disease & $1.1 \%$ & $0.2 \%$ & 0.21 & $0.6 \%$ & 0.93 & $0.6 \%$ \\
\hline Framingham 10 year CVD risk & $3.2 \%$ & $2.8 \%$ & 0.99 & $2.8 \%$ & $<0.001$ & $3.1 \%$ \\
\hline
\end{tabular}

1. Younger parturients were women aged 34/35-39 at the time of their first childbirth delivery.

2. Older parturients were women aged 40-44 at the time of their first childbirth delivery.

*All comparisons between the general population and three other groups have statically significant differences ( $\mathrm{p}$-values <.01) except for the nonsignificant difference in percentage with diabetes between the general population and the persistent nulliparous group

\section{RESULTS}

- Over the follow-up, 952 women gave birth for the first time between the ages of 35-39, 673 gave birth between the ages of 40-44, and 8,354 women remained persistently nulliparous.

- Older women were found to have more gestational diabetes $(6.9 \%$ vs $4.3 \%, \mathrm{p}-0.036)$ and preeclampsia $(4.0 \%$ vs $1.9 \%, \mathrm{p}=0.015)$ we found no difference between the two parturients groups in the prevalence of cardiovascular and metabolic disease outcomes at age 45.

- Older parturients also did not have more adverse cardiovascular outcomes when compared to the general population or persistent nulliparas.

\section{CONCLUSIONS}

In this study cohort, women who had their first birth at an older age did not have an increased risk for intermediate cardiovascular complications. 